\title{
Tevatron Reverse Injection
}

\author{
S. Saritepe and G. Annala \\ Fermi National Accelerator Laboratory \\ P.O. Box 500, Batavia, Illinois 60510
}

June 1993 


\section{Disclaimer}

This report was prepared as an account of work sponsored by an agency of the United States Government. Neither the United States Government nor any agency thereof, nor any of their employees, makes any warranty, express or implied, or assumes any legal liability or responsibility for the accuracy, completeness, or usefulness of any information, apparatus, product, or process disclosed, or represents that its use would not infringe privately owned rights. Reference herein to any specific commercial product, process, or service by trade name, trademark, manufacturer, or otherwise, does not necessarily constitute or imply its endorsement, recommendation, or favoring by the United States Government or any agency thereof. The views and opinions of authors expressed herein do not necessarily state or reflect those of the United States Government or any agency thereof. 


\title{
Tevatron Reverse Injection
}

\author{
S. Saritepe* and G. Annala \\ Fermi National Accelerator Laboratory ${ }^{\dagger}$ \\ Batavia, Illinois, USA
}

June 25, 1993

\section{Introduction}

In the new injection scenario antiprotons are injected onto a helical orbit in the Tevatron in order to avoid the detrimental effects of the beam-beam interaction at $150 \mathrm{GeV}$. The new scenario required changes in the tuning procedure. Antiprotons are too precious to be used for tuning, therefore the antiproton injection line has to be tuned with protons by reverse injecting them from the Tevatron into the Main Ring (MR).

Previously, the reverse injection was performed in one supercycle. One batch of uncoalesced bunches was injected into the Tevatron and ejected after 40 seconds. Then the orbit closure was performed in the MR. In the new scheme the lambertson magnets have to be moved and separator polarities have to be switched, activities that cannot be completed in one supercycle. Therefore, the reverse injection sequence was changed. This involved the redefinition of TVBS clock event $\$ D 8$ as MRBS $\$ D 8$ [1] thus making it possible to inject 6 proton batches (or coalesced bunches) and eject them one at a time on command, performing orbit closure each time in the MR.

\section{Reverse (Antiproton) Injection Line}

The details of the reverse injection line can be found in reference [2]. Here we reproduce the injection line sketch and the circuit diagram showing the reverse injection shunt from the reference [2] for completeness (Fig.(1) and Fig.(2)).

\section{$3 \quad$ Reverse Injection Timing}

The timing issues for the reverse injection are discussed in detail in reference [3]. Here we repeat the table showing the reverse injection sequence (Table 1).

\section{Tuning Procedure}

There are basically four modes of tuning for the reverse injection.

(1) Routine tuning, i.e. orbit closure before each shot,

*current address: SSCL, MS 1040, 2550 Beckleymeade Ave. Dallas, TX 75237

'Operated by Universities Research Association,Inc., under contract with the United States Department of Energy 


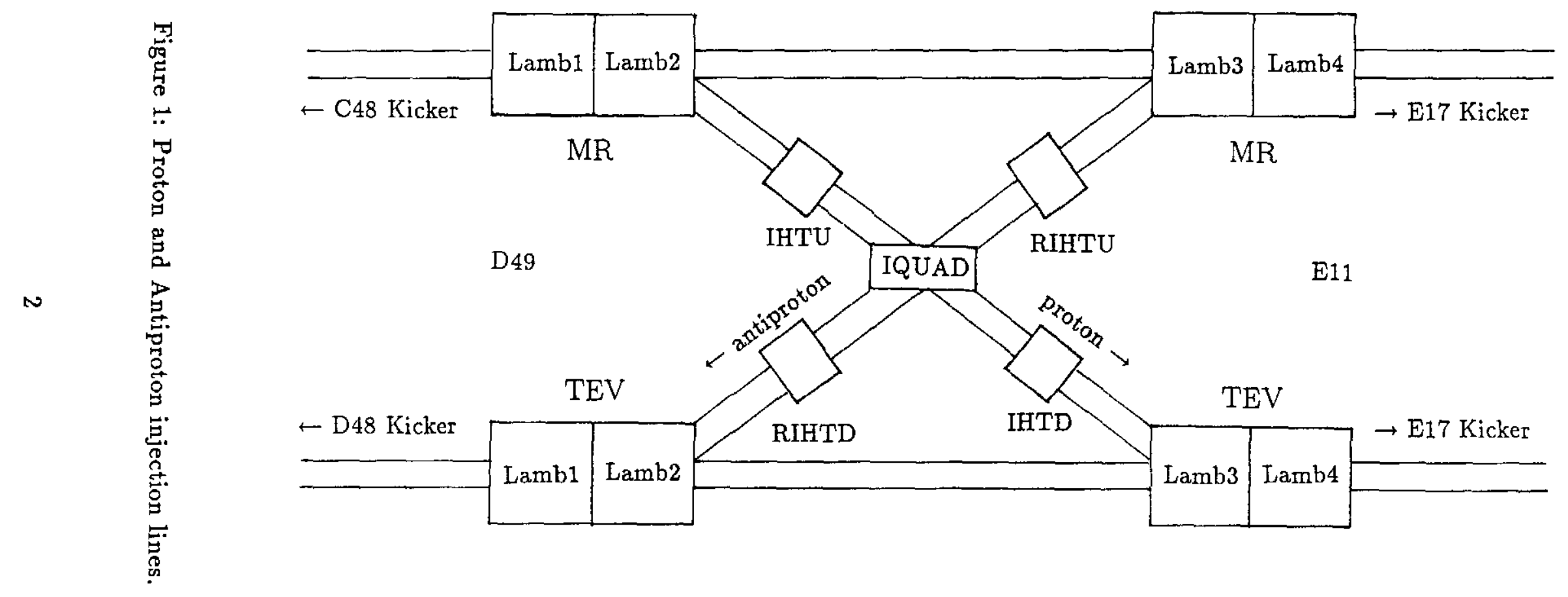




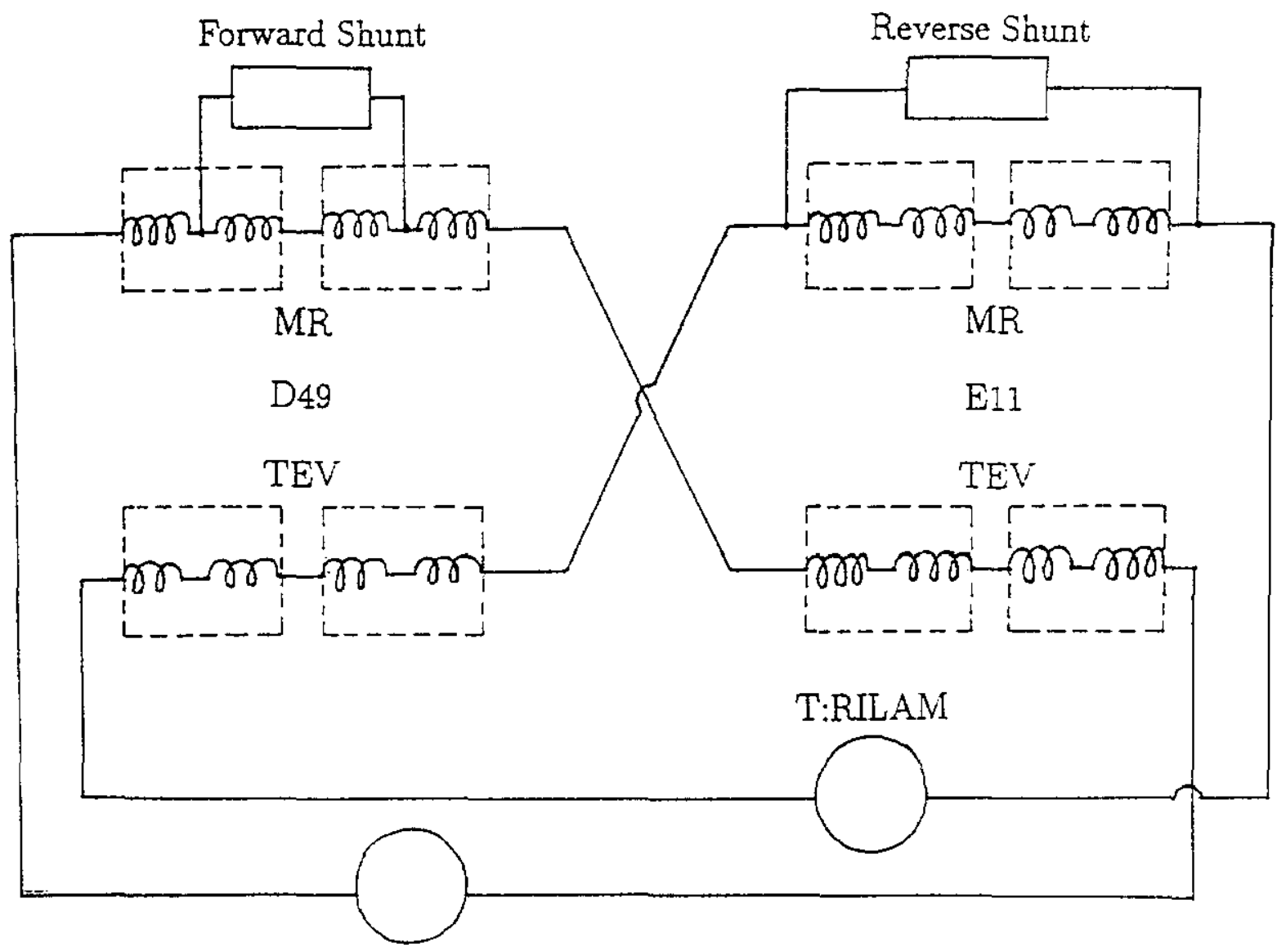

T:FILAM

Figure 2: Circuit diagram showing the shunt connections. This diagram was drawn from tunnel observations by G.Annala. If the forward shunt and the reverse shunt both remove, for instance, $5 \mathrm{Amps}$ from the circuit, the angle adjustment provided by the reverse shunt will be twice as big as that provided by the forward shunt. 


\begin{tabular}{|l|l|l|}
\hline \multicolumn{3}{|c|}{ REVERSE PROTON INJECTION } \\
Event & Delay & Description \\
\hline \hline & Sequencer command & Disable \$4D. Wait 8 sec. \\
\hline $4 \mathrm{~B}$ & Sequencer trigger & Tev:Abort clean-up \\
\hline & Sequencer command & Disable $\$ 4 \mathrm{~B}$. \\
\hline \multicolumn{3}{|c|}{ Load sequencer files 10,13 } \\
\hline \multicolumn{3}{|c|}{ Inject 6 coalesced proton bunches into the Tevatron on 6 \$2B cycles } \\
\hline & Sequencer command & Tev:Move the proton lambertsons out. \\
\hline & Sequencer command & $\begin{array}{l}\text { Tev:Set the separator polarities to "-. } \\
\text { (C:C1SVP, C:B1SHP, C:B0SHP) }\end{array}$ \\
\hline C3 & Sequencer trigger & $\begin{array}{l}\text { Open the helix. } \\
\text { (Camac-465 tables are preloaded by C49) }\end{array}$ \\
\hline & Sequencer command & Insert \$20 cycles in the timeline. \\
\hline 20 & TLG & Reset: MR cycle for reverse injection. \\
\hline 22 & $<20>0.6$ sec & MR:Start ramp to 150 GeV. \\
\hline 25 & $<20>2.5048$ sec & MR:Start flattop at 150 GeV. \\
\hline & $<20>7.5$ sec & $\begin{array}{l}\text { Start the Tevatron time bump (handled by } \\
\text { E0 456 cards, see Operations Bull. 1233 }\end{array}$ \\
\hline
\end{tabular}

Sequencer complex command: "eject protons $\mathrm{Pn}_{\mathrm{n}}$ " $(\mathrm{n}=1-6)$

\begin{tabular}{|l|l|l|}
\hline & & $\begin{array}{l}\text { Execute Sequencer file 35. This file sets up } \\
\text { MR BPM events to take data on \$20 cycle only. }\end{array}$ \\
\hline C1 & $\begin{array}{l}\text { Align markers. Only occurs once after "setting" } \\
\text { at 150 GeV. It is triggered off a } 177 \text { timer. }\end{array}$ \\
\hline $\begin{array}{l}\text { D8 } \rightarrow 55 \\
(\text { MRBS })\end{array}$ & $<20>13.8 \mathrm{sec}$ & Enable MRBS \$D8. \\
\hline & $<\mathrm{D} 8>2.038 \mathrm{mrev}$ & Initiate Tev $\rightarrow$ MR transfer. \\
\hline & $<\mathrm{D} 8>1.409 \mathrm{mrev}$ & $\begin{array}{l}\text { Fire the Tev D48 kicker. Rise time is 3 } \mu \mathrm{sec} . \\
\text { Half-sine wave form. }\end{array}$ \\
\hline & & Disable \$D8. \\
\hline
\end{tabular}

end complex command "eject protons $\mathrm{Pn}$ "

\begin{tabular}{|l|l|l|}
\hline 26 & $<20>13.9748 \mathrm{sec}$ & MR:End of $\$ 20$ cycle flattop (150 GeV). \\
\hline \multicolumn{3}{|c|}{ eject all 6 bunches, tune the antiproton injection line } \\
\hline C0 & Sequencer trigger & Close the helix. \\
\hline & Sequencer command & $\begin{array}{l}\text { Set C:C1SVP, C:B1SHP, C:B0SHP } \\
\text { polarities to "+". }\end{array}$ \\
\hline & Sequencer command & Move the proton lambertsons in. \\
\hline & Sequencer command & Remove the $\$ 20$ cycle from TLG. \\
\hline
\end{tabular}

Table 1: The new reverse injection timing. The transfer cogging offsets are $0,186,371,557,742,928$ RFCYC, for $\mathrm{P} 1$ through $\mathrm{P} 6$ respectively. TCLK event $\$ 55$ triggers the Bull's Eye plot. 
(2) Adjustments after orbit smoothing,

(3) Adjustments after helix amplitude changes,

(4) Reverse Injection checkout. This is done during startup after long shutdowns.

Routine Tuning:

In the new reverse injection scheme, 6 proton bunches are injected onto the "injection orbit". Proton lambertsons are moved out, the separator polarities are switched, then the separators are powered. The resultant orbit is the same one that the antiproton beam would be launched onto. Therefore, ejecting proton bunches from this orbit is equivalent to injecting antiprotons onto it. The orbit closure has to be performed in the MR. The caution here is that the MR-BPMs have to take data only on $\$ 20$ cycles. Usually, there are $\$ 29$ cycles in the timeline following $\$ 20$ 's. If the MR-BPM system reads the orbits on $\$ 29$ cycles the $\$ 20$ orbits will be overwritten. Now the first thing the "complex" sequencer command "eject P1,P2,P3,P4,P5,P6" does is to execute sequencer file 35. Commands in this file make sure that MR-BPMs take data only on $\$ 20$ cycles.

The orbit closure program has recently been automated [4]. One interrupt on the field "REFRESH DATA" is sufficient to obtain the most recent first turn and closed orbits.

Adjustments after orbit smoothing:

If the position and angle changes resulting from orbit smoothing are small, a simple orbit closure using $\mathrm{T} 120$ would be sufficient. If the orbit changes around $\mathrm{E} 0$ are substantial then one has to adjust the reverse injection time bump. This entails using the console page C6 (DIPOLE, subpage 4). Here one adjusts the time bump amplitudes using the already defined MULTs. Tuning procedure is as follows:

(1) Make sure that the antiproton lambertsons are in the "injection" position.

If the "reverse injection" aggregate was properly executed the proton lambertsons must be already in the "stored beam" position, ie, sufficiently away from the beam. (2) Do not issue the "eject P1,P2,P3 ..." command. Make sure that there is a $\$ 20$ in the timeline. The reverse injection time-bump will play at every $\$ 20$. This means that the proton beam will be getting closer to the antiproton lambertson notch.

(3) plot the losses (T:LILM1U, T:LILM2U) as a function of time. Trigger the plot on event $\$ 20$, time scale can be taken as 12 to 16 seconds (beam transfer - middle of the time bump period - is $13.8 \mathrm{sec}$ from the $\$ 20$ reset).

(4) Increase the D49 horz. position (using the MULT) until losses appear, then decrease the D49 slightly and try ejecting the beam, if ejection is successful perform closure in the MR. The horizontal angle is critically important. This means that the MULT corresponding to the E11 horz. position should be adjusted also to get the angle right. One has to experiment until loss-free ejection (using coalesced beam) is achieved.

(5) In principle a reverse injection time bump in the vertical plane is not needed. One may have to create one if it helps the kicker or the shunt.

(6) The goal in this tuning is to find the compromise between the kicker strength, shunt current and the losses.

Adjustments after helix amplitude changes:

Helix amplitude is subject to change during the collider run. Again a simple orbit closure will be sufficient in most cases. If, however, the change in the helix amplitude is big, then one must perform orbit closure in steps. The helix amplitude is changed in steps and an orbit closure is performed each time. Once the final closure values are obtained these values must be entered in the Sequencer file \#13.

\section{Reverse Injection checkout:}


A complete checkout of the reverse injection may be necessary after long shutdowns. We divide this tuning procedure into two parts.

I) DRY RUN

(1) Kill beam.

(2) Change the time line. There has to be at least one $\$ 20$ in the timeline.

(3) Plot devices T:IQUAD, T:RIHTD, T:RIHTU as a function of time. These devices ramp in $\$ 20$ cycles. Watch the T:IQUAD, it should ramp with the reverse polarity.

(4) Check the T119 parameter page. Make sure that T:RILAM, T:ILAMS, T:ILAMSK are enabled.

(5) Call up C4 (Bull's Eye Plot), start the plot, trigger it on $\$ 55$. This is just an exercise to see that the plot is updating.

(6) Call up T105, start the D48 Kicker trace-scope. Make sure it is updating on $\$ 55$.

II) CHECKOUT WITH BEAM

(1) Issue the "reverse injection" aggregate in the sequencer.

(2) Watch C4

(3) Watch T:LILM1U, T:LILM2U (loss monitors on the antiproton injection lambertsons).

(4) Eject P1

(5) Look at the closure in the MR

(6) Once a good closure is achived in the MR, enter the settings for T:RIHTD, T:E17K3, T:RILAM, T:ILAMS in the sequencer file \#13. Otherwise the next time you reverse inject (or inject antiprotons) the old closure values will be set by the sequencer.

\section{Orbits}

It is paramount to have hardcopies of the Tevatron and MR orbits for the reverse injection. One needs the closed orbit and the last turn orbit in the Tevatron and the closed orbit and first turn orbit in the Tevatron. These orbits are shown in figures $3,4,5,6,7,8$.

\section{Lessons learned during January 1992 studies}

During the January 1992 studies, the reverse injection time bump had to be recreated since we did not know the best last turn orbit in the Tevatron that would allow a lossfree ejection. In addition to the changes in the time-bump the closed orbit positions and angles had to changed also. Table 2 and 3 below show the history of the closed orbit at D49. Table 4 and 5 show the history of the E11 position. Reasons for the changes are also given in the tables. After the January studies, during the shutdown the D49 Tevatron lambertsons were raised by $8 \mathrm{~mm}$. The closed orbit and time-bumps changed again during collider commissioning. Since the closed orbits and time-bump may change in the future again, the orbits shown in this report should be taken as hints for the future adjustments.

\subsection{Problems encountered during reverse injection from the helix during January 1992 studies}

In the beginning there were hardware problems. The first time we tried reverse injection the T:IQUAD reversing switch was stuck in the reverse polarity and did not switch back 

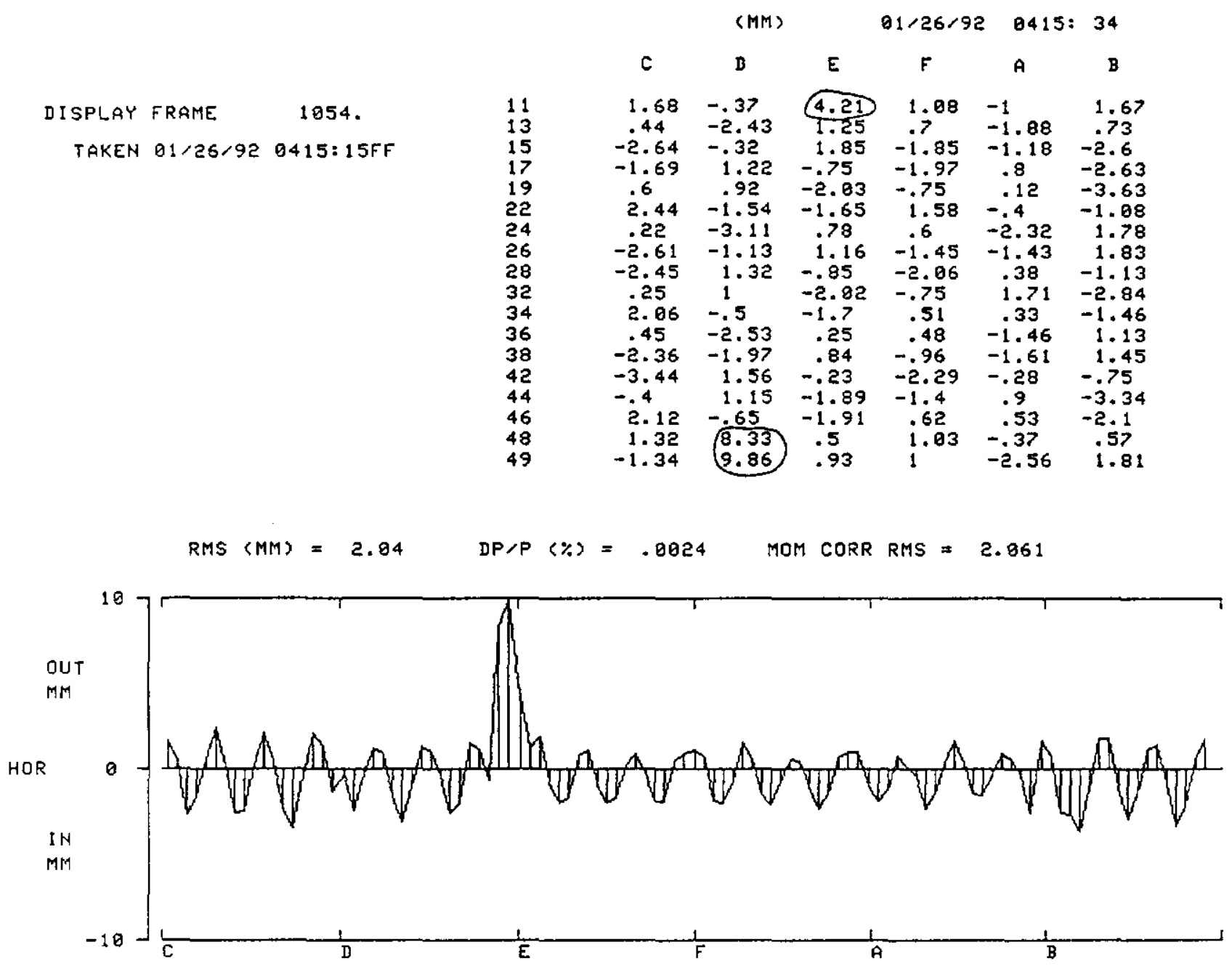

Figure 3: Horizontal closed orbit in the Tevatron (60\% Helix), taken just prior to reverse transfer. 


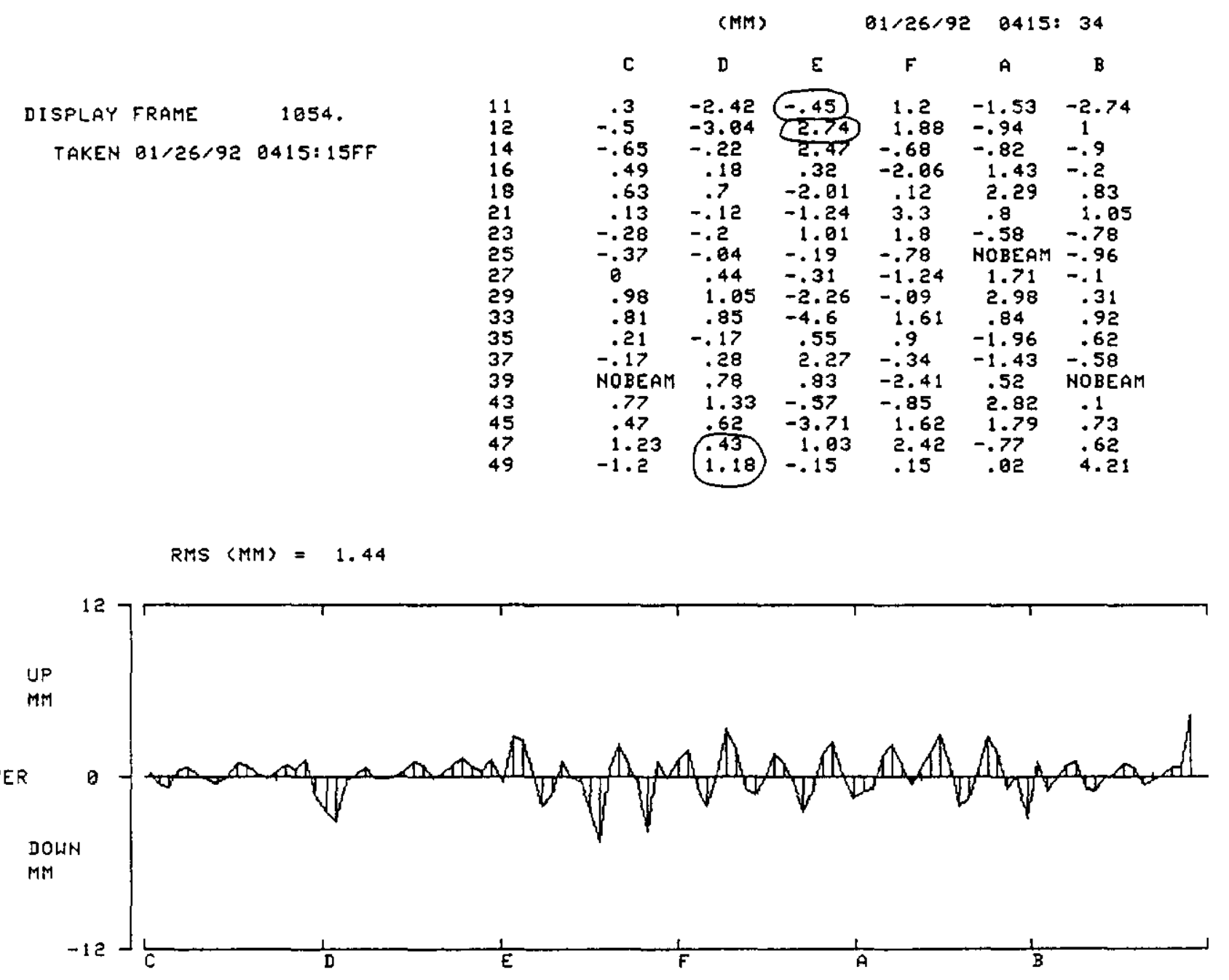

Figure 4: Vertical closed orbit in the Tevatron (60\% Helix), taken just prior to reverse transfer. 


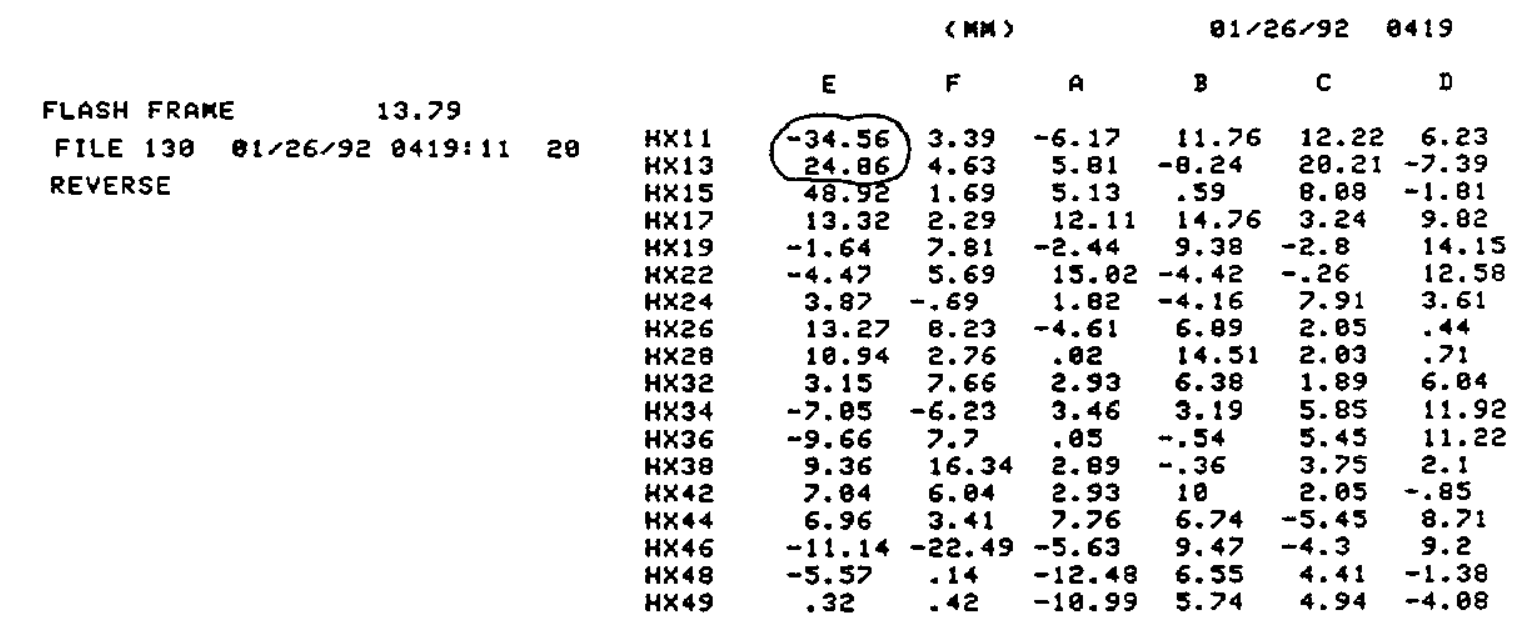

$M R$

RMS $(M M)=9.822 \quad D P / P(\%)=$

.1028 MOM CORR RMS $=8.982$

HR

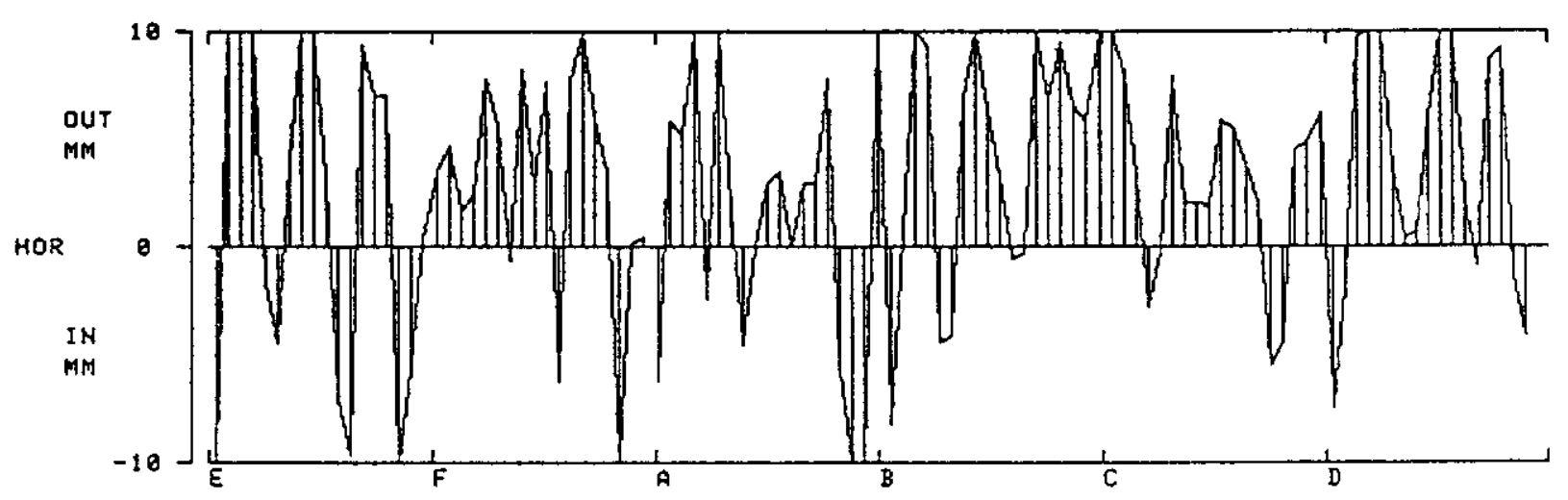

Figure 5: First turn horizontal orbit in the MR (60\% Helix). 

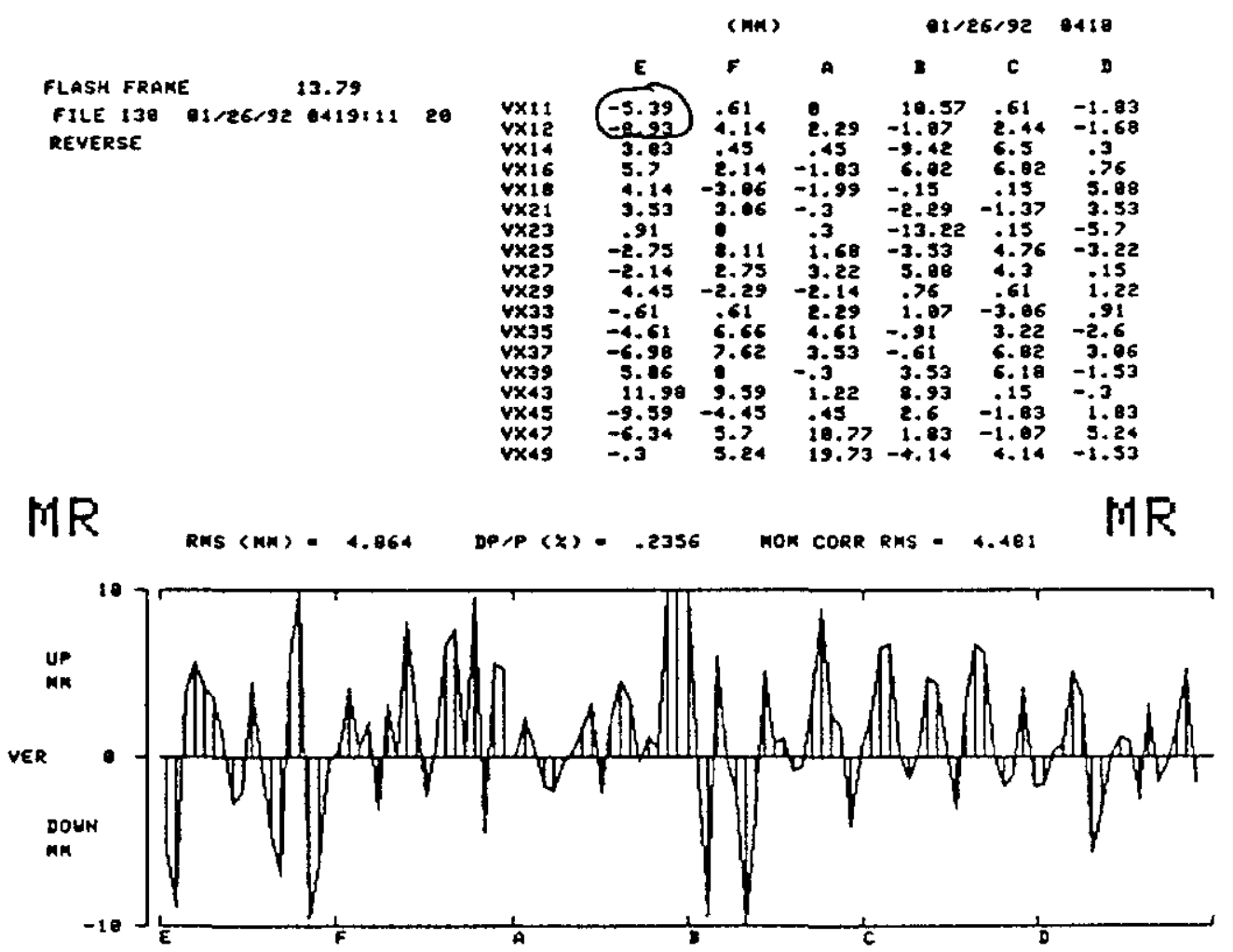

Figure 6: First turn vertical orbit in the MR (60\% Helix). 


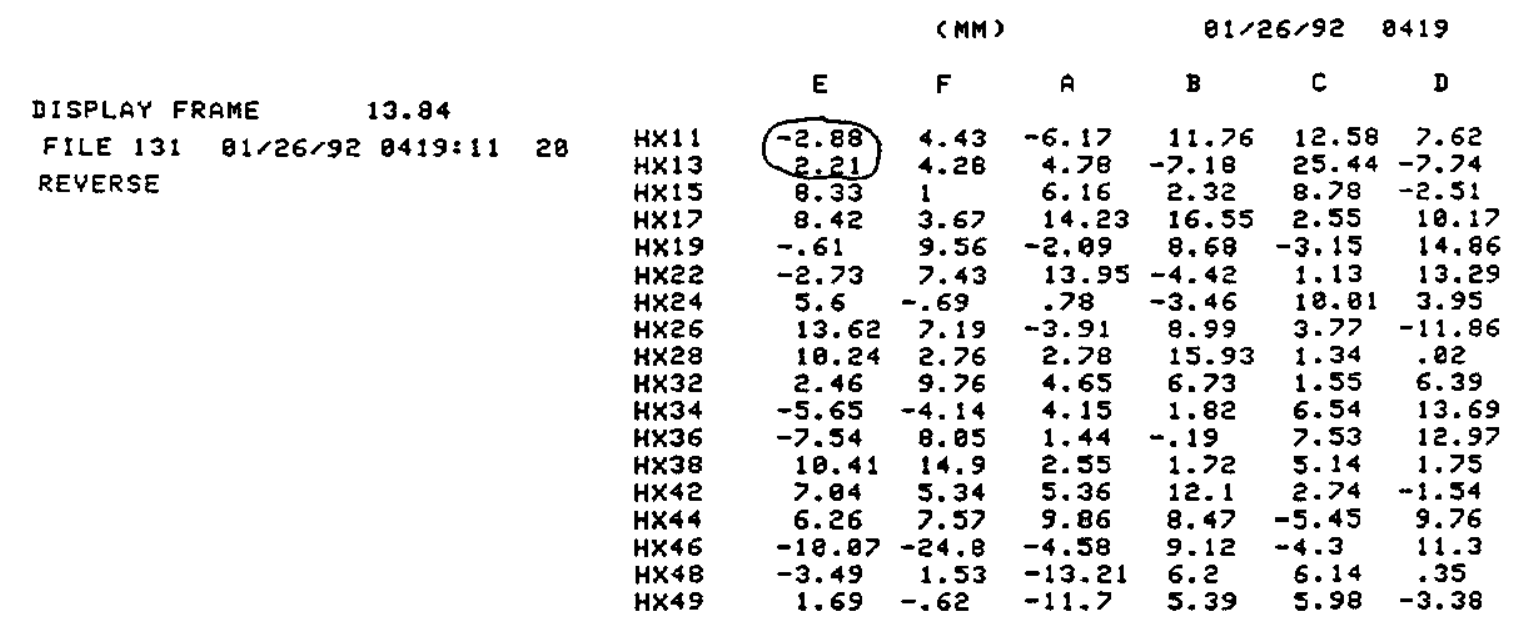

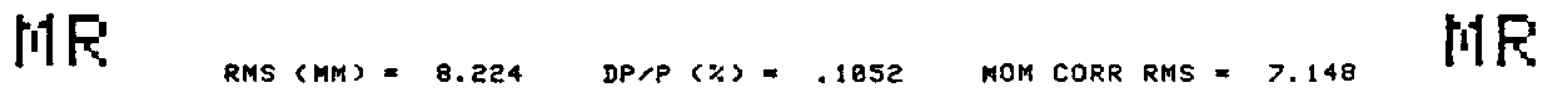

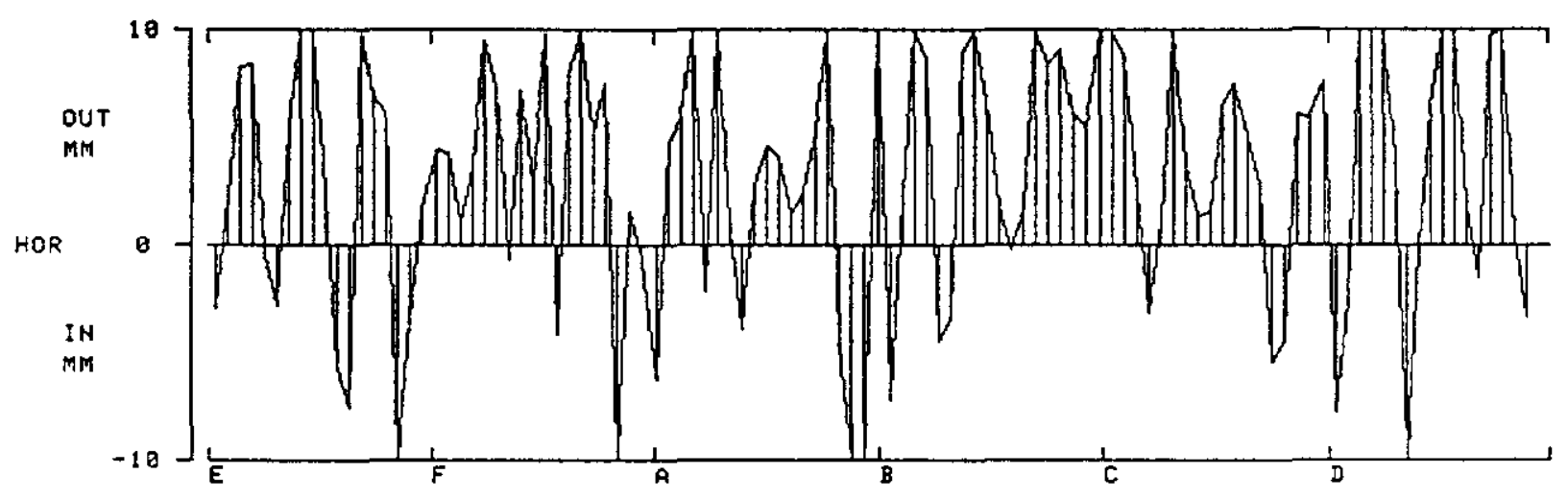

Figure 7: Horizontal closed orbit in the MR (60\% Helix). 


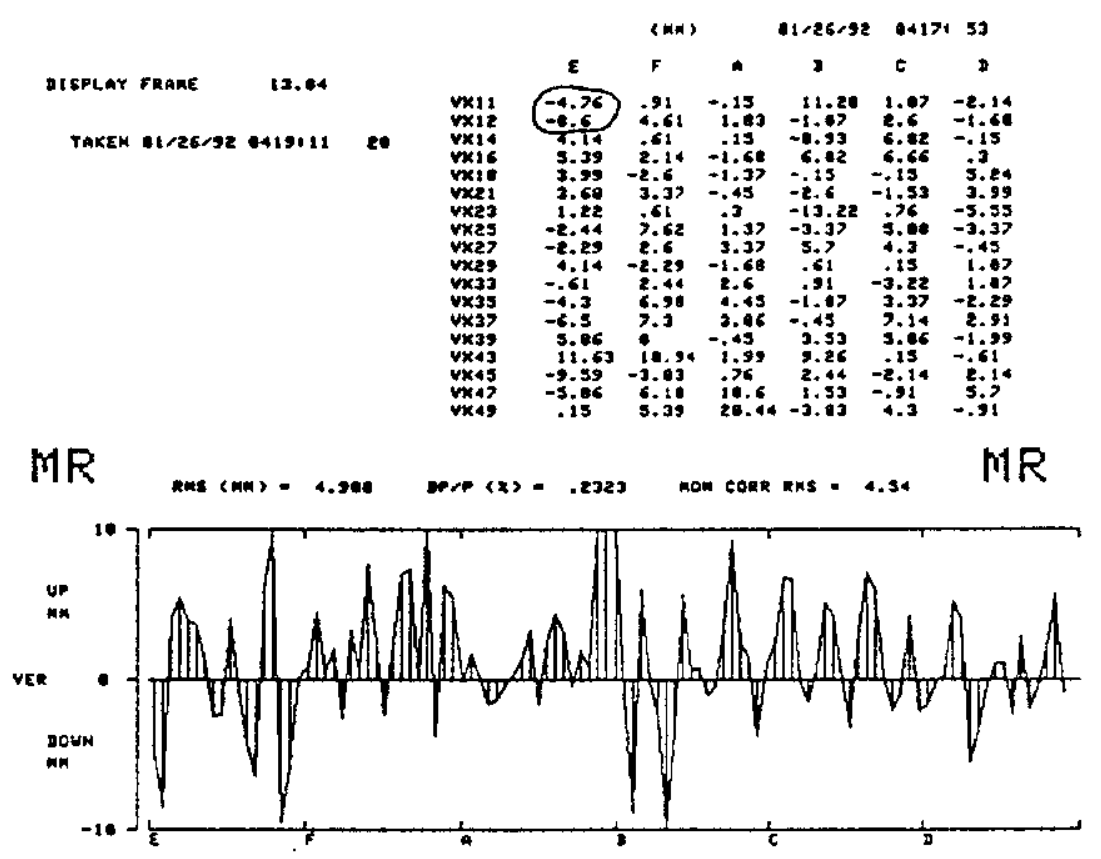

Figure 8: Vertical closed orbit in the MR (60\% Helix). 


\begin{tabular}{|l|r|l|}
\hline \hline Date & $\begin{array}{r}\text { Horizontal } \\
\text { Position }\end{array}$ & Explanation \\
\hline Jan 8 & $4 \mathrm{~mm}$ & Beginning of studies. \\
\hline Jan 15 & $9 \mathrm{~mm}$ & $\begin{array}{l}\text { to prevent scraping on the } \bar{p} \text { lambertson } \\
\text { during the forward injection }\end{array}$ \\
\hline Jan 20 & $12 \mathrm{~mm}$ & same reason above \\
\hline Jan 27 & $12 \mathrm{~mm}$ & End of studies. \\
\hline
\end{tabular}

Table 2: History of the horizontal closed orbit position at D49 during January 1992 studies.

\begin{tabular}{|l|r|l|}
\hline \hline Date & $\begin{array}{r}\text { Vertical } \\
\text { Position }\end{array}$ & Explanation \\
\hline Jan 8 & $4 \mathrm{~mm}$ & Beginning of studies. \\
\hline Jan 20 & $1 \mathrm{~mm}$ & to provide vertical aperture for the $60 \%$ helix \\
\hline Jan 27 & $1 \mathrm{~mm}$ & End of studies. \\
\hline
\end{tabular}

Table 3: History of the vertical closed orbit position at D49 during January 1992 studies.

\begin{tabular}{|l|r|l|}
\hline \hline Date & $\begin{array}{r}\text { Horizontal } \\
\text { Position }\end{array}$ & Explanation \\
\hline Jan 8 & $7 \mathrm{~mm}$ & Beginning of studies. \\
\hline $\operatorname{Jan} 27$ & $7 \mathrm{~mm}$ & End of studies. \\
\hline
\end{tabular}

Table 4: History of the horizontal closed orbit position at E11 during January 1992 studies.

\begin{tabular}{|l|r|l|}
\hline \hline Date & $\begin{array}{r}\text { Vertical } \\
\text { Position }\end{array}$ & Explanation \\
\hline Jan 8 & $0 \mathrm{~mm}$ & Beginning of studies. \\
\hline Jan 20 & $-2.7 \mathrm{~mm}$ & $\begin{array}{l}\text { could not change the MRE11↔MRE12 } \\
\text { angle because the shunt was running at 15 Amps, } \\
\text { lowered VPE11 in the TEV instead }\end{array}$ \\
\hline Jan 27 & $-2.7 \mathrm{~mm}$ & End of studies. \\
\hline
\end{tabular}

Table 5: History of the vertical closed orbit position at E11 during January 1992 studies. 
to the forward polarity. Replacement of this switch cost us 6 hours. Then we proceeded to changing the reverse injection time bumps. In our early trials we were unable to establish circulating beam in the MR. We later discovered that the D48 kicker was shorted. Diagnosis and replacement of this magnet cost us 5 shifts.

We learned to be careful about the "prepare for beam" and other timers in the MR BPM system. For instance, the MR BPM readings for the $\$ 20$ cycles were being overwritten by the $\$ 29$ cycles in the absence of proper precautions. In the current setup (as of Aug 1,1992) "prepare for beam" in the MR is taken care of by the sequencer (file 35).

Later difficulties in the reverse injection involved the angles and the vertical aperture at D49. The new closed orbit positions at D49 and E11 made it necessary to change the horizontal time-bump angle between D49 and E11. The initial solution was to have $21 \mathrm{~mm}$ at $\mathrm{D} 49$ and $6 \mathrm{~mm}$ at $\mathrm{E} 11$ when the time-bump was playing. This worked fine, however, when the proton helix was opened, beam was scraping on something that looked like the backend of the field-free region of the D49 lambertsons. The speculation here is that it is possibly the flange not the backend of the field-free region. Nevertheless, the time-bump at D49 was reduced to $11 \mathrm{~mm}$, the "stored beam" position for the lambertsons was changed from -930 mils to -600 mils. This solved the horizontal aperture problem.

The vertical aperture problem was at D49 as well. We could not open the proton helix to $100 \%$. We lowered the closed orbit position by $3 \mathrm{~mm}$, we wanted to lower it further by $8 \mathrm{~mm}$, but the shunt was running at 0 Amps so we could not do it. This limited the helix amplitude at $150 \mathrm{GeV}$ to $60 \%$ of the design value. At $900 \mathrm{Gev}$ the helix could be opened to $100 \%$ percent since the helix amplitude shrinks with energy.

\section{Appendix A: Kicker waveforms}

The kicker waveforms are examined in T105. One has to make sure that the trace updates on $\$ 55$ events. Any deviation from the waveforms shown in Fig.(9) and Fig.(10) indicates kicker hardware problems.

\section{References}

[1] R.J.Ducar, "Why TVBS \$D8 Became MRBS \$D8", Unpublished Note (July 1991).

[2] S.Saritepe and G.Annala, "Beam Transfer at E0: An Overview", FERMILAB-TM1790 (1993).

[3] S.Saritepe and G.Annala, "Tevatron Injection Timing", FERMILAB-TM-1792 (1993).

[4] L. Winterowd made changes in the T120 code. It now refreshes FLASH and DISPLAY data automatically in one interrupt. 


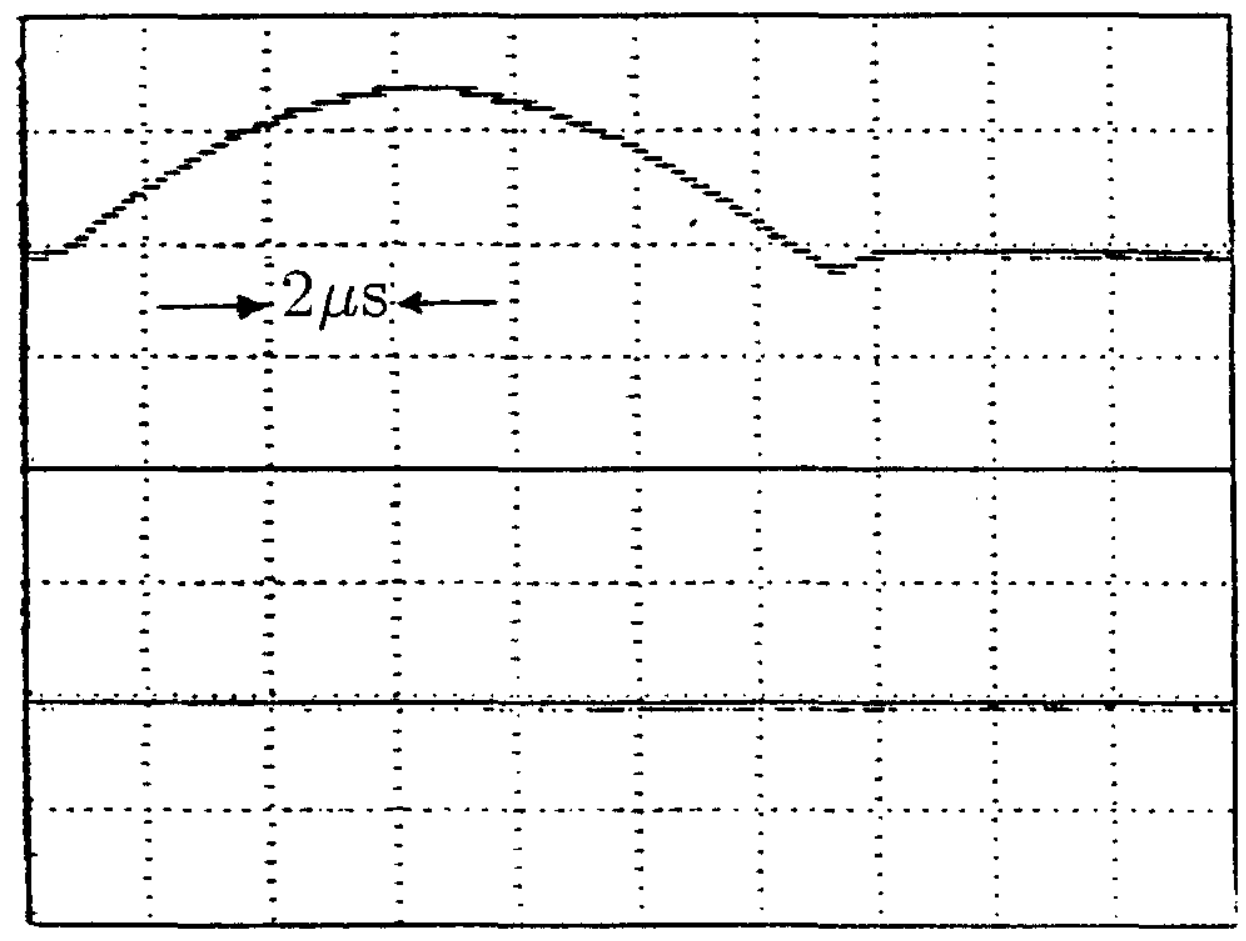

Figure 9: Waveform for the MR E17 Kicker. 


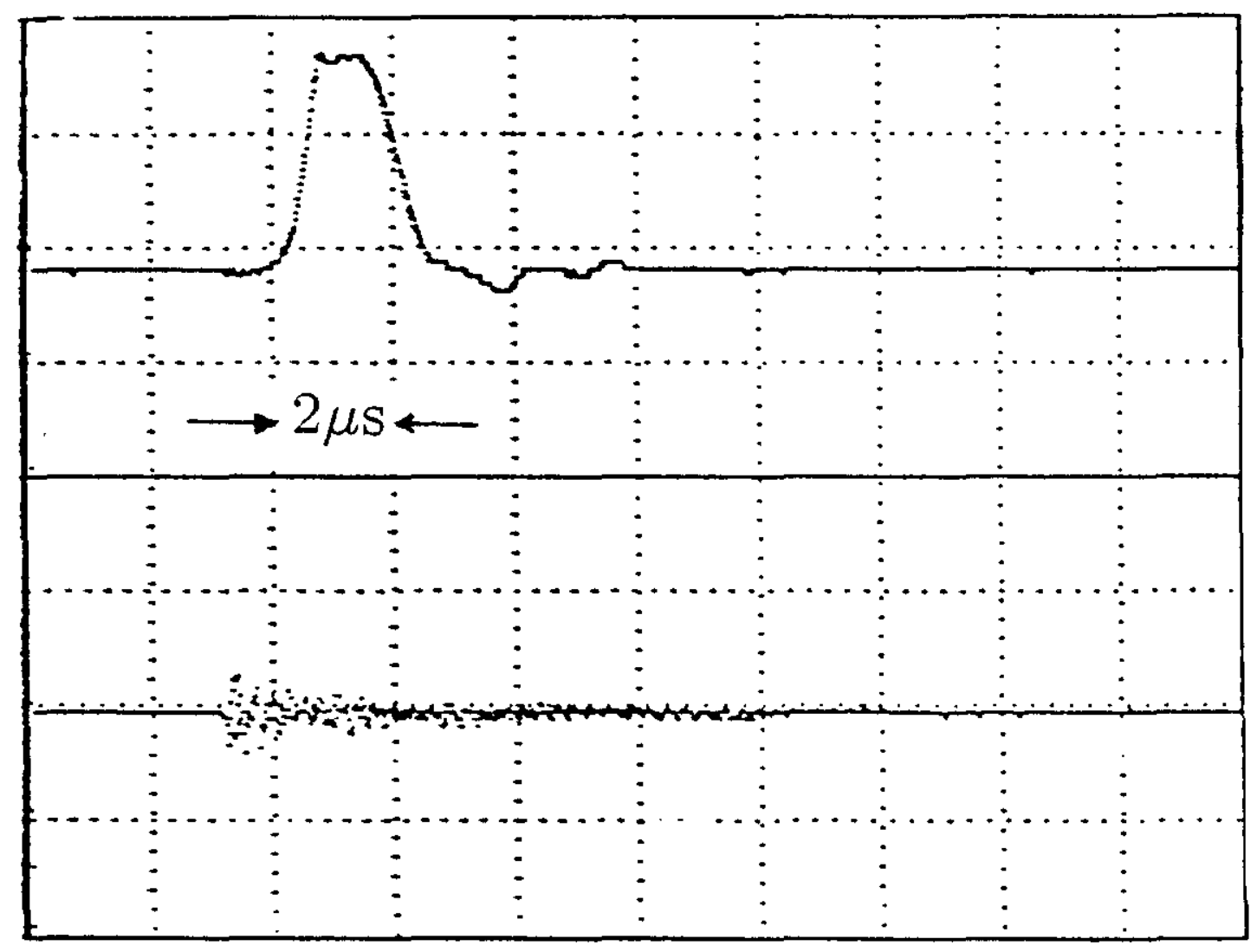

Figure 10: Waveform for the Tevatron D48 Kicker. 